\title{
Increased apoptotic activity on inflammatory human placentas in spontaneous abortions during the first and second trimester of gestation: a histochemical and immunohistochemical study
}

\author{
Theodora-Eleftheria Deftereou ${ }^{1}$, Maria Lambropoulou ${ }^{1}$, Ekaterini Chatzaki ${ }^{2}$, \\ Maria Koffa $^{3}$, Petros Ypsilantis ${ }^{4}$, Olga Pagonopoulou ${ }^{5}$, Iordana Grammatikopoulou, \\ Elias Papadopoulos ${ }^{1}$, Alexandros Papalambros ${ }^{1}$, Emmanouil Kontomanolis $^{6}$, \\ Nikolas Papadopoulos ${ }^{1}$
}

${ }^{1}$ Laboratory of Histology-Embryology, Democritus University of Thrace, Greece

${ }^{2}$ Laboratory of Pharmacology, Democritus University of Thrace, Greece

${ }^{3}$ Department of Molecular Biology and Genetics, Democritus University of Thrace, Greece

${ }^{4}$ Laboratory of Experimental Surgery and Surgical Research,

Democritus University of Thrace, Greece

${ }^{5}$ Laboratory of Physiology, Democritus University of Thrace, Greece

${ }^{6}$ Department of Obstetrics and Gynecology, Democritus University of Thrace, Greece

\begin{abstract}
The aim of this study was to investigate the role of apoptotic markers on inflammatory human placentas from spontaneous abortions during the first and second trimester of gestation and compare them to those without inflammation. Paraffin-embedded specimens from 76 placentas were investigated by conventional histology and immunohistochemistry using monoclonal antibodies against M30, Caspase 3, Caspase 8 and Caspase 9, as well as the terminal deoxynucleotidyl tranferase-mediated deoxyuridine triphosphate nick end labeling method. A higher prevalence of expression of apoptotic markers (94.4\%) was observed in placentas associated with chorioamnionitis in comparison with those without inflammation. Our observations confirm that apoptosis is strikingly prevalent in placentas diagnosed with histologic chorioamnionitis, while the inflammation induces cell death. (Folia Histochemica et Cytobiologica 2012, Vol. 50, No. 1, 118-124)
\end{abstract}

Key words: placenta, apoptosis, immunohistochemistry, congenital disorders, chorioamnionitis

\section{Introduction}

Two distinct types of cell death, apoptosis and necrosis, have been described, based on differences at the morphological, biochemical and molecular level [1].

Correspondence address: M. Lambropoulou,

Histology-Embryology Medical School,

Democritus University of Thrace,

Dragana, 68100, Alexandroupolis, Greece;

tel./fax: + 302551030558 ;

e-mail:mlambro@med.duth.gr
Every day, 50-70 billion cells die in the human body, due to the phenomenon of apoptosis [2]. Apoptosis is the commonest type of programmed cell death in eukaryotic cells and requires the activation of intracellular biochemical pathways [1]. The main characteristics of this procedure are the following: cell shrinking, changes in the cell membrane, chromatin condensation, nuclear fragmentation, chromosomal DNA fragmentation, creation of apoptotic bodies, breakdown of mitochondria, and release of cytochrome $\mathrm{C}$ [2]. The family of cysteine proteases, also 
called caspases, plays a critical role in the molecular apoptotic pathway [1].

Apoptosis is essential in many physiological processes, including embryonic development of tissues, organs and limbs, and development of the nervous system as well as the physiological tissue turn-over in adult organs [3].

Many studies have suggested that apoptosis plays a significant role in the development, remodeling and aging of the placenta. For example, activation of the Fas system is responsible for the placental villous trophoblast turnover [4-6]. It has been suggested that the rate of trophoblast apoptosis may be altered under pathologic conditions [7-9]; however, no comparative studies have been conducted so far. During chorioamnionitis, the commonest condition of fetal membrane inflammation [10], alteration in the apoptotic index may change the balance between cell death and cell survival, affecting placental physiological development [11].

A panel of antigens related to apoptosis was used in our study for a complete evaluation of the apoptotic activity in the placental tissues. A useful early apoptotic marker in tissues is M30, a specific neoepitope deriving from a caspase cleavage site within Cytokeratin $18[12,13]$, an early event in the apoptotic process [14]. Cytokeratin 18 is a component of cytoskeleton of the trophoblasts that are of epithelial origin [15]. Thus, M30 has been previously suggested as a suitable marker for studying early trophoblast apoptosis [16]. The anti-Caspase 3 antibody detects endogenous levels of full length Caspase $3(35 \mathrm{kDa})$ [17]. This protein has been identified as a key mediator of apoptosis in mammalian cells [18], acting as a 'henchman' that leads the cell to suicide [19]. Caspase 8 binds the Fas-associated death domain (FADD) [20] causing its activation [21]. Caspase 8 leads also to the activation of other descending caspases, such as Caspase 9, which prepare the cell to undergo apoptosis [20]. Another member of caspase's family of proteins is pro-caspase 9 [22]. Pro-caspase 9 is activated from Apaf- 1 with proteolysis to give mature Caspase 9 [23]. This molecule can activate a caspase cascade, including caspase 3, 6 and 7 [22]. Finally, the well-established TUNEL method was used for detecting apoptosis, identifying apoptotic cells by using terminal deoxynucleotidyl transferase (TdT) [17, 24]. The TUNEL technique identifies cells in the final steps of the apoptotic cascade [14]. TUNEL, first described by Gavrieli et al. in 1992 [25], has several advantages in apoptosis detection, such as rapidity, increased sensitivity and discrimination of apoptosis from necrosis [26].
In the present study, apoptosis was evaluated in placental membranes from spontaneous abortions, diagnosed with chorioamnionitis, congenital disorders or ischemia due to nuchal cord, in order to reveal differences indicating involvement in the pathophysiological process.

\section{Material and methods}

Tissue specimens. 76 placental samples from spontaneous abortions during the first and second trimester of pregnancy were used. Tissue biopsies were collected at the villous parenchyma from both the central and the peripheral part of each placenta. Standard pathological examination was performed for diagnosis by hematoxylin/eosin staining. Chorioamnionitis was diagnosed in 54 samples (Group A), fetal congenital malformations were found in 14 samples (Group B), and ischemia due to nuchal cord in eight cases (Group C). The study was conducted according to the guidelines for the analysis of fetal cells and tissues, and was approved by the Regional Committee of Ethics.

Immunohistochemistry. The samples were formalin-fixed (10\% of phosphate buffer) and paraffin-embedded. Four $\mu \mathrm{m}$ serial sections were cut from the blocks using a Leica RM2030 rotary microtome (Leica Microsystems, Germany) and were mounted on slides. They were then deparaffinized in an oven at $80^{\circ} \mathrm{C}$ for 30 minutes, followed by incubation in xylene and the slides were rehydrated in descending ethanol series. Endogenous peroxidase activity was quenched by 15 minutes incubation of slides with $0.3 \% \mathrm{H}_{2} \mathrm{O}_{2}$. For immunohistochemistry, the biotin-streptavidin method was applied using the Kit CHEMICON IHC Select-Immunoperoxidase secondary detection system (Chemicon, USA). Slides were washed in phosphate buffer saline (PBS) for 5 minutes and then blocking reagent was added for 10 minutes. Slides were then incubated for 60 minutes in a humidified atmosphere with one of the monoclonal antibodies as follows: M30 CytoDeath (1:80 dilution in 10\% Normal Rabbit Serum (NRS)/PBS, Alexis Biochemicals, San Diego, CA, USA), antiCaspase 3 (1:80 dilution in 10\%NRS/PBS, Cell Signaling Technology, Hitchin, UK), anti-Caspase 8 (Spring Bioscience, Pleasanton, Canada) and anti-Caspase 9 (Spring Bioscience, Pleasanton, Canada). In parallel, negative control slides were incubated with $10 \%$ NRS/PBS. After washing with PBS, the biotinylated secondary antibody was added for 10 minutes, followed by streptavidin HRP incubation for 10 minutes. Finally, bound antibody complexes were stained for $10 \mathrm{~min}$ with $0.05 \%$ diaminobenzidine chromogen (DAKO, Carpinteria, CA, USA). Finally, sections were briefly counterstained with Mayer's hematoxylin, mounted and examined under a Nikon microscope of $\times 400$ magnification. An homogenous, light brown staining of the cytoplasm revealed positive cells. 
Terminal deoxynucleotidyl transferase-mediated deoxyuridine triphosphate nick end labeling (TUNEL). TUNEL was performed using the In Situ Death Detection kit (Roche, Mannheim, Germany) according to the manufacturer's instructions. Briefly, deparaffinized $4 \mu \mathrm{m}$ tissue sections were incubated with $50 \mu \mathrm{l}$ of Label and Enzyme Solution for 60 $\min$ at $37^{\circ} \mathrm{C}$ in a humidified atmosphere in the dark. The biotin-labeled cleavage sites were then detected by reaction with HRP conjugated streptavidin and visualized by diaminobenzidine chromogen. As a negative control, slides were incubated with $50 \mu \mathrm{l}$ Label Solution. Light brown staining of the nucleus and cytoplasm indicated positive cells. All slides were photographed with Nikon Digital Sight SD-SI (Nikon Corporation, Japan).

Evaluation of immunostaining. Each slide was individually evaluated and scored in a blinded fashion by two independent observers (M.L. and N.P.). Positivity was graded in a four-scale system as follows 0 : absent, $1:<10 \%, 2$ : $10-50 \%, 3:>50 \%$ positive cells in the total number of cells counted per field (at least ten). Positive samples were considered when the score was different from 0 as well as exhibiting both morphological features of apoptosis on light microscope (cytoplasmic fragmentation and nuclear condensation).

Statistical analysis. Percentages of positive tissues among the three studied groups were compared using the chi-square test (SPSS, v. 12). Significance was set at a $\mathrm{p}$ value $<0.05$.

\section{Results}

The study's specimen characteristics are summarized in Table 1. Table 2 presents the incidence of positive immunostaining for the apoptotic markers examined in the three groups. Table 3 shows the expression levels of the apoptotic markers in the three groups.

Immunohistochemical staining for all apoptotic markers, Caspase 3, 8, and 9 and M30 showed cytoplasmic localization in syncytiotrophoblast, whereas Caspase 3 had also cytoplasmic immunoreactivity. In group A (chorioamnionitis), 51/54 (94.4\%) of the cases expressed all the apoptotic markers examined, and three cases were found negative. Two of them derived from male fetuses miscarried in the $20^{\text {th }}$ and $23^{\text {rd }}$ gestational week, while the third sample derived from a female fetus aborted in the $16^{\text {th }}$ week of gestation. In group B (congenital malformations), only $1 / 14(7.2 \%)$ was positive for the apoptotic marker Caspase 3, whereas all other immunohistochemical staining was found negative. Finally, all eight placental samples from group C (ischemia) were negative for all the apoptotic markers examined.

Statistical analysis revealed significantly higher percentages of positive tissues in group A in comparison with the other two groups $(\mathrm{p}<0.05)$. Mean expression levels of Caspase 3, 8 and 9 in group A were $2.52 \pm 0.88,2.57 \pm 0.86$ and $2.51 \pm 0.88$ respectively, and for M30 $2.48 \pm 0.88$. TUNEL staining also confirmed that placental tissues from group A had significantly increased levels of apoptotic cells; with mean levels in TUNEL score $2.66 \pm 0.77$, as compared to the other two groups. The TUNEL-positive cells were found in the trophoblast and stromal cells. Increased TUNEL-positive staining in syncytiotrophoblast layer was shown in the placenta in group $\mathrm{A}$ (Figures 1, 2).

Table 1. Aborted embryo characteristics

\begin{tabular}{|l|c|c|c|c|c|c|}
\hline \multirow{2}{*}{ Group } & \multicolumn{3}{|c|}{ Number of cases } & \multicolumn{2}{c|}{ Embryo sex } & \multirow{2}{*}{ Cause of embryonic death } \\
\cline { 2 - 5 } & \multirow{3}{*}{ Total } & \multicolumn{2}{|c|}{ Gestational age } & \multirow{2}{*}{ Male } & Female & \\
\cline { 2 - 6 } & $\mathbf{9}^{\text {th }} \mathbf{- 1}^{\text {th }}$ week & $\mathbf{1 8}^{\text {th }} \mathbf{- 2 4}^{\text {th }}$ week & 31 & 23 & Chorioamnionitis \\
\hline A & 54 & 18 & 36 & 8 & 6 & Congenital disorders \\
\hline B & 14 & 3 & 11 & 5 & 3 & Ischemia due to nuchal cord \\
\hline
\end{tabular}

Table 2. Incidence of positive apoptotic marker immunostaining in the placenta of spontaneously aborted embryos

\begin{tabular}{|l|c|c|c|c|c|c|c|}
\hline \multirow{2}{*}{ Diagnosis } & \multirow{2}{*}{ Group } & \multirow{2}{*}{$\mathbf{n}$} & \multicolumn{4}{|c|}{ Incidence (\%) of apoptotic marker positive immunostaining } \\
\cline { 4 - 9 } & & & Caspase 3 & Caspase 8 & Caspase 9 & M30 & TUNEL \\
\hline Histologic chorioamnionitis & A & 54 & 94.4 & 94.4 & 94.4 & 94.4 & 94.4 \\
\hline Congenital disorders & B & 14 & 7.2 & 0 & 0 & 0 & 0 \\
\hline Ischemic death & C & 8 & 0 & 0 & 0 & 0 & 0 \\
\hline
\end{tabular}

$\mathrm{p}<0.05$ group A vs. B and C 
Table 3. Expression levels in apoptotic markers in chorioamnionitis and congenital disorders

\begin{tabular}{|c|c|c|c|c|c|}
\hline \multirow[t]{2}{*}{ Apoptotic marker } & \multirow[t]{2}{*}{ Groups } & \multicolumn{4}{|c|}{ Expression level } \\
\hline & & $\mathbf{0}$ & 1 & 2 & 3 \\
\hline \multirow[t]{2}{*}{ Caspase 3} & $\begin{array}{l}\text { Chorioamnionitis } \\
\qquad(\mathrm{n}=54)\end{array}$ & $\begin{array}{c}3 \\
(5.55 \%)\end{array}$ & $\begin{array}{c}5 \\
(9.26 \%)\end{array}$ & $\begin{array}{c}8 \\
(14.82)\end{array}$ & $\begin{array}{c}38 \\
(70.37 \%)\end{array}$ \\
\hline & $\begin{array}{l}\text { Congenital disorders } \\
(\mathrm{n}=14)\end{array}$ & $\begin{array}{c}13 \\
(92.8 \%)\end{array}$ & $\begin{array}{c}1 \\
(7.2 \%)\end{array}$ & $\begin{array}{c}0 \\
(0 \%)\end{array}$ & $\begin{array}{c}0 \\
(0 \%)\end{array}$ \\
\hline \multirow[t]{2}{*}{ Caspase 8} & $\begin{array}{l}\text { Chorioamnionitis } \\
\quad(\mathrm{n}=54)\end{array}$ & $\begin{array}{c}3 \\
(5.55 \%)\end{array}$ & $\begin{array}{c}4 \\
(7.41 \%)\end{array}$ & $\begin{array}{c}6 \\
(11.11 \%)\end{array}$ & $\begin{array}{c}41 \\
(75.93 \%)\end{array}$ \\
\hline & $\begin{array}{c}\text { Congenital disorders } \\
(\mathrm{n}=14)\end{array}$ & $\begin{array}{c}14 \\
(100 \%)\end{array}$ & $\begin{array}{c}0 \\
(0 \%)\end{array}$ & $\begin{array}{c}0 \\
(0 \%)\end{array}$ & $\begin{array}{r}0 \\
(0 \%)\end{array}$ \\
\hline \multirow[t]{2}{*}{ Caspase 9} & $\begin{array}{l}\text { Chorioamnionitis } \\
\quad(\mathrm{n}=54)\end{array}$ & $\begin{array}{c}3 \\
(5.55 \%) \\
\end{array}$ & $\begin{array}{c}5 \\
(9.26 \%) \\
\end{array}$ & $\begin{array}{c}7 \\
(12.97 \%) \\
\end{array}$ & $\begin{array}{c}39 \\
(72.22 \%) \\
\end{array}$ \\
\hline & $\begin{array}{c}\text { Congenital disorders } \\
(\mathrm{n}=14)\end{array}$ & $\begin{array}{c}14 \\
(100 \%)\end{array}$ & $\begin{array}{c}0 \\
(0 \%)\end{array}$ & $\begin{array}{c}0 \\
(0 \%)\end{array}$ & $\begin{array}{c}0 \\
(0 \%)\end{array}$ \\
\hline \multirow[t]{2}{*}{ M30 } & $\begin{array}{l}\text { Chorioamnionitis } \\
\qquad(\mathrm{n}=54)\end{array}$ & $\begin{array}{c}3 \\
(5.55 \%)\end{array}$ & $\begin{array}{c}5 \\
(9.26 \%)\end{array}$ & $\begin{array}{c}9 \\
(16.67 \%)\end{array}$ & $\begin{array}{c}37 \\
(68.52 \%)\end{array}$ \\
\hline & $\begin{array}{l}\text { Congenital disorders } \\
\quad(\mathrm{n}=14)\end{array}$ & $\begin{array}{c}14 \\
(100 \%)\end{array}$ & $\begin{array}{c}0 \\
(0 \%)\end{array}$ & $\begin{array}{c}0 \\
(0 \%)\end{array}$ & $\begin{array}{c}0 \\
(0 \%)\end{array}$ \\
\hline \multirow[t]{2}{*}{ TUNEL } & $\begin{array}{l}\text { Chorioamnionitis } \\
\quad(\mathrm{n}=54)\end{array}$ & $\begin{array}{c}3 \\
(5.55 \%)\end{array}$ & $\begin{array}{c}1 \\
(1.85 \%)\end{array}$ & $\begin{array}{c}7 \\
(12.97 \%)\end{array}$ & $\begin{array}{c}43 \\
(79.63 \%)\end{array}$ \\
\hline & $\begin{array}{l}\text { Congenital disorders } \\
(\mathrm{n}=14)\end{array}$ & $\begin{array}{c}14 \\
(100 \%)\end{array}$ & $\begin{array}{c}0 \\
(0 \%)\end{array}$ & $\begin{array}{c}0 \\
(0 \%)\end{array}$ & $\begin{array}{c}0 \\
(0 \%)\end{array}$ \\
\hline
\end{tabular}

\section{Discussion}

It is well known that apoptosis is a nodal cellular phenomenon with a significant role for the orderly operation of the multicellular organism as a whole [27, $28]$. In the apoptotic process, a number of molecules are involved directly or indirectly, e.g. FasL/FasR, TNF- $\alpha$ /TNFR1, Bcl-2 family, and as a result several cellular activities are also influenced $[29,30]$. The placenta's growth rate, structure and cellular composition are modified upon implantation of the developing embryo into the maternal endometrium during pregnancy [31]. Apoptosis plays a critical role during placental evolution [32]. In normal term placentas, Smith et al. [7] found an apoptotic rate of $0.05 \%$. Our results show differential apoptotic activity in placentas from spontaneous abortions due to different causes in the first and second trimesters of pregnancy. Indeed, we report the expression of multiple apoptotic markers in placentas from spontaneously aborted fetuses, diagnosed for chorioamnionitis, congenital malformation or ischemia due to nuchal cord. Immunohistochemical evaluation showed high apoptotic levels in the cases diagnosed with inflammation, contrary to the other tissues where apoptosis was absent.

Chorioamnionitis is an inflammation of the chorion and amnion that can be caused by a bacterial infection ascending into the uterus from the mother's urogenital tract [33]. Specifically, the infection can begin in the vagina, anus or rectum and move up and into the uterus where the fetus is located [33]. According to Salafia et al. [34], histologic chorioamnionitis is described as the presence of severe inflammatory changes on examination of membrane roll and chorionic plate of the placenta. Chorioamnionitis is observed in approximately $10 \%$ of all births [35] and its severity is classified in grades from 1 to 3 [36]. Acute chorioamnionitis is recognized by the intense infiltration of neutrophils that expand from the subchorionic space throughout the chorion [37].

Our results showed that the prevalence of all apoptotic markers was substantially higher in the samples observed with chorioamnionitis compared to those from abortions attributed to congenital malformations or ischemia, where the apoptotic expression was almost absent. These results indicate a strong relationship between inflammation and apoptosis in the placental tissue.

Our results are in accordance with other studies addressing the relation of apoptosis to inflammation in the placental tissue [11, 14, 21, 38, 39]. Tanir et al. [38] showed that the presence of infection was found to be highly associated with rupture of membrane (ROM) in placentas (53.8\%), a condition closely related to apoptosis. Fortunato et al. [40] suggested that the main underlying factor leading to apoptosis in placentas from ROM cases was a lipopolysaccharide 

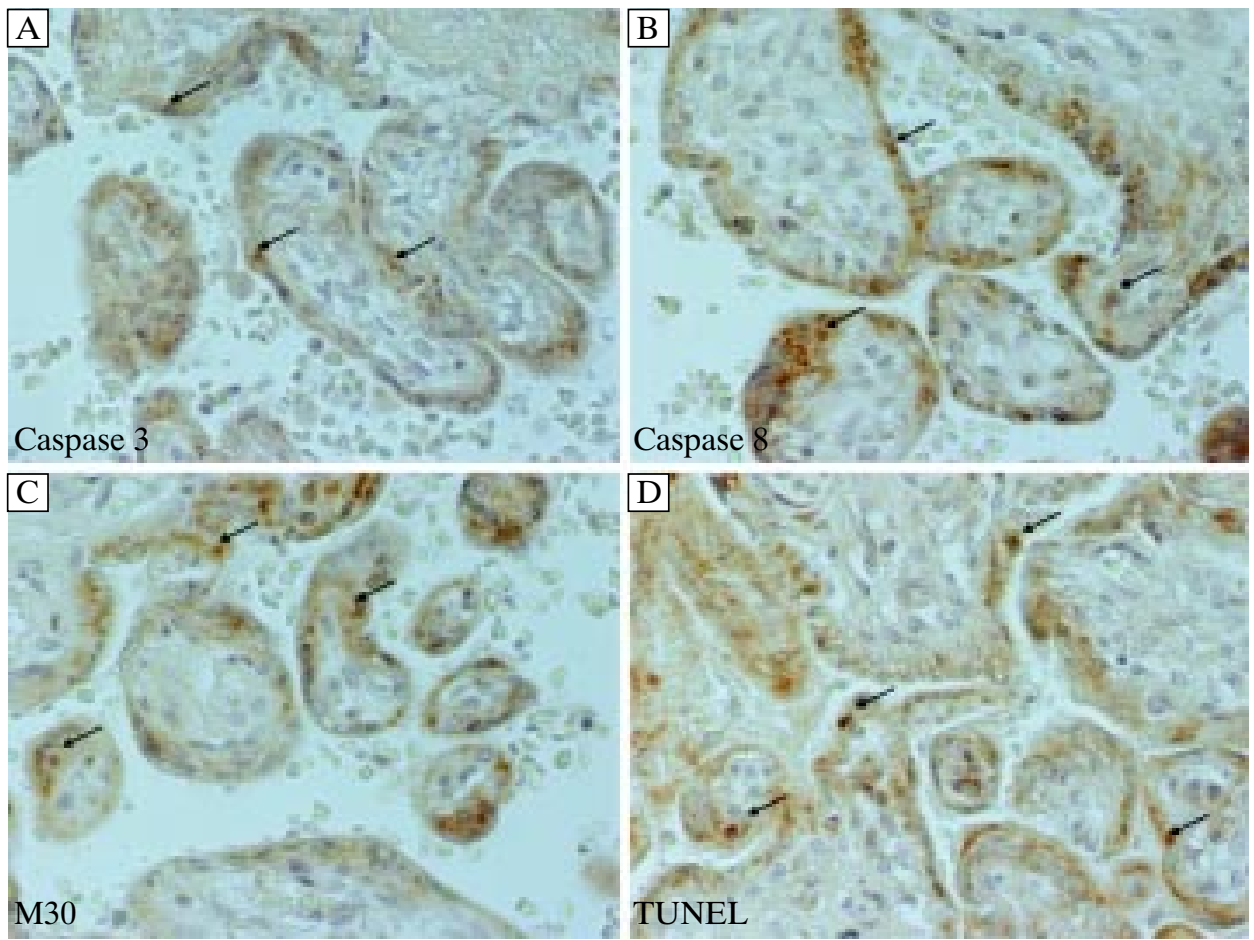

Figure 1. Representative micrographs immunostaining for Caspase 3 (A), Caspase 8 (B), M30 (C), and TUNEL (D) in placental tissue diagnosed with chorioamnionitis. Positive trophoblast cells are marked with arrows (original magnification $\times 400$ )
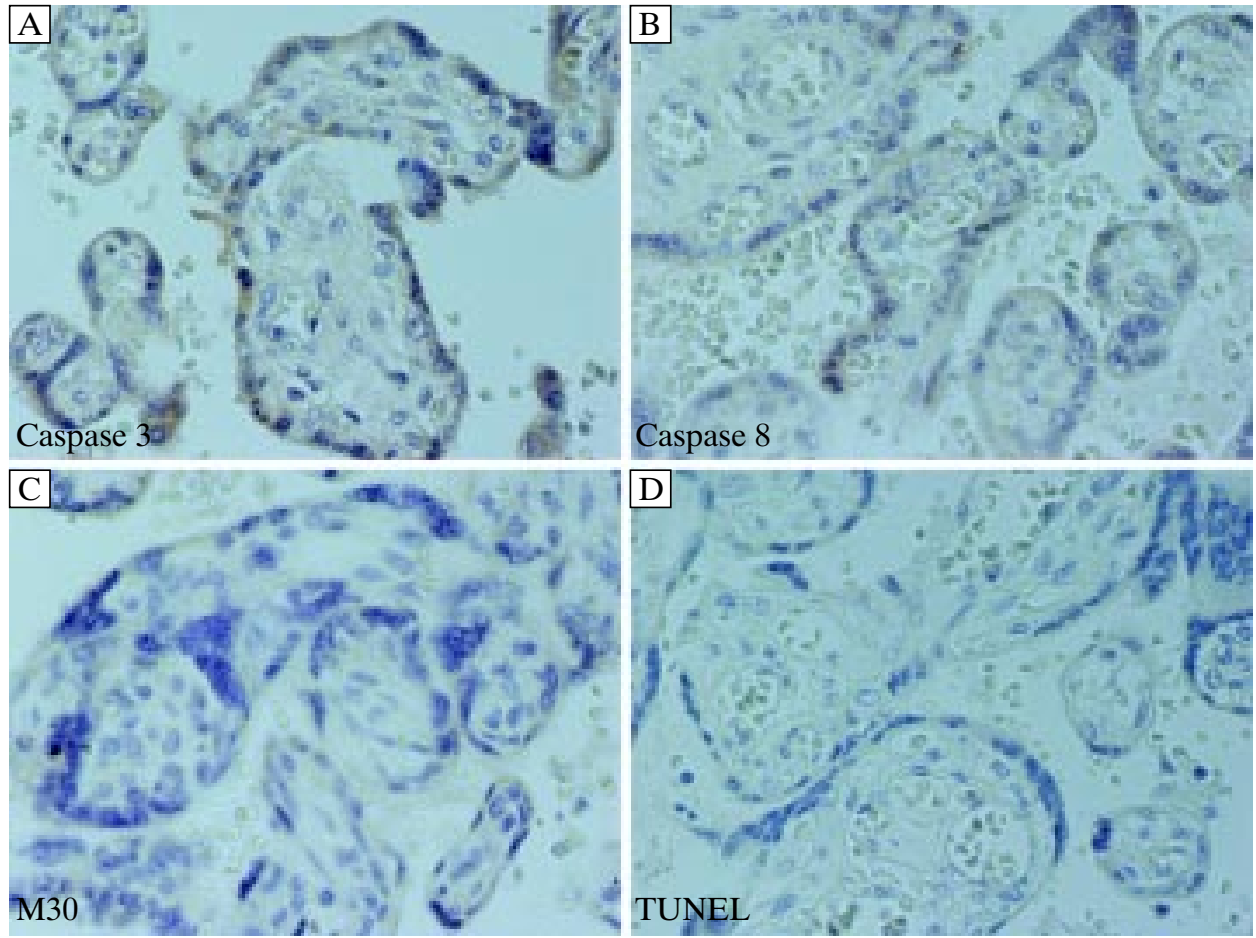

Figure 2. Representative micrographs immunostaining for Caspase 3 (A), Caspase 8 (B), M30 (C), and TUNEL (D) (congenital disorders and ischemia, original magnification $\times 400$ )

from gram-negative bacterial infections. These lipopolysaccharides stimulate TNF- $\alpha$ (tumor necrosis factor $\alpha$ ), inducing an intracellular apoptotic caspase pathway. Using TUNEL, Murtha et al. [11] observed that chorion laeve from subjects with histologically verified chorioamnionitis had significantly more ap- 
optotic nuclei compared to those without infection. Recently, George et al. [41] provided TUNEL data supporting the hypothesis that inflammation accelerates cell death and destruction of the chorion.

Generally, when cells undergo apoptosis, there is no inflammatory response; however, when peritoneal macrophages and dendritic cells incur Fas-mediated apoptosis, cytokines and neutrophil chemotactic factors are released [42]. This implies that in the case of inflammation, certain cellular molecules are secreted in order to activate the programmed cell death [37]. A remarkable feature of chorioamnionitis is the activation of the placental immune cells, leading to the release of inflammatory molecules into the placental microenvironment, such as cytokines [37]. This evokes the infiltration of the chorion, amnion and placental villi by neutrophils, a hallmark of chorioamnionitis [37]. The proinflammatory cytokines have cytotoxic activity to trophoblasts, inducing their apoptosis [43].

A possible mechanism for inflammation in chorioamnionitis involves the apoptotic pathway of FasL/ /Fas [44]. The bacterial infection may activate placental immune cells to produce cytokines, which in turn induces Fas-mediated apoptosis of trophoblasts. Thus, as more cytokines and chemotactic factors are released, the inflammatory process is amplified [37].

Based on the results of this study, we conclude that the presence of histologic chorioamnionitis in the placenta from spontaneous abortions during the first and second trimester is relevant with high apoptotic activity. It is well understood that the inflammatory process affects the balance between survival and cell death inducing apoptosis. As placental tissues play an important role in the maintenance of pregnancy, inflammation-related apoptosis can significantly contribute to the mechanism leading to spontaneous abortion.

It will be of interest to further investigate the role of the different apoptotic pathways in this context, as well as in relation to the diversity of the bacterial infection leading to spontaneous abortions.

\section{Acknowledgments}

The skilful technical assistance of Irene Apostolou is gratefully acknowledged.

\section{References}

1. Kerr JF, Wyllie AH, Currie AR. Apoptosis: a basic biological phenomenon with wide-ranging implications in tissue kinetics. Br J Cancer. 1972;26:239-257.

2. Thompson CB. Apoptosis in the pathogenesis and treatment of disease. Science. 1995;267:1456-1462.

3. Kam PC, Ferch NI. Apoptosis: mechanisms and clinical implications. Anaesthesia. 2000;55:1081-1093.
4. Smith SC, Baker PN, Symonds EM. Placental apoptosis in normal human pregnancy. Am J Obset Gynecol. 1997; 177:57-65.

5. Chan CCW, Lao TT, Cheung ANY. Apoptotic and proliferative activities in first trimester placentae. Placenta. 1999;20:223-227.

6. Huppertz B, Frank HG, Reister F, Kingdom JC, Reister F, Kaufmann P. Villous cytotrophoblast regulation of the syncytial apoptotic cascade in the human placenta. Histochem Cell Biol. 1998;110:495-508.

7. Smith SC, Baker PN, Symonds EM. Increased placental apoptosis in intrauterine growth restriction. Am J Obstet Gynecol. 1997; 177:1395-1401.

8. Allaire AD, Ballenger KA, Wells SR, McMahon MJ, Lessey BA. Placental apoptosis in preeclampsia. Obstet Gynecol. 2000;96:271-276.

9. Axt R, Meyberg R, Mink D et al. Immunohistochemical detection of apoptosis in human term and post-term placenta. Clin Exp Obste Gynecol. 1999;26:56-59.

10. Nakatsuka M, Asagiri K, Kimura Y, Kamada Y, Tada K, Kudo T. Generation of peroxynitrite and apoptosis in placenta of patients with chorioamnionitis: possible implications in placental abruption. Hum Reprod. 1999;14:1101-1106.

11. Murtha AP, Auten R, Herbert WN. Apoptosis in the chorion laeve of term patients with histologic chorioamnionitis. Infect Dis Obstet Gynecol. 2002;10:93-96.

12. Krol J, Mengele K, Ottl-Mantchenko I et al. Ex vivo detection of apoptotic trophoblast cells applying flow cytofluorometry and immunocytochemistry using M30 antibody directed to the cytokeratin 18 neo-epitope. Int J Mol Med. 2005;16:415-420.

13. Huppertz B, Frank HG, Kaufmann P. The apoptosis cascade - morphological and immunohistochemical methods for its visualization. Anat Embryol. 1999;1:1-18.

14. Austgulen R, Chedwick L, Vogt Isaksen C, Vatten L, Craven C. Trophoblast apoptosis in human placenta at term as detected by expression of a cytokeratin 18 degradation product of caspase. Arch Pathol Lab Med. 2002;126:1480-1486.

15. Frank HG, Genbacev O, Blaschitz A et al. Cell culture models of human trophoblast - primary culture of trophoblast - a workshop report. Placenta. 2000;21:120-122.

16. Huppertz B. Molecular markers for human placental investigation. Methods Mol Med. 2006;121:337-350.

17. Erhardt JA et al. Activation of caspase-3/caspase-3-like activity in rat cardiomyocytes by an RGD peptide, but not the GPIIb/IIIa antagonist lotrafiban. Thromb Res. 2001;103:143-148.

18. Budihardjo I et al. Biochemical pathways of caspase activation during apoptosis. Ann Rev Cell Dev Biol. 1999; 15:269-290.

19. Chandrasekar B et al. Activation of intrinsic and extrinsic proapoptotic signaling pathways in interleukin-18-mediated human cardiac endothelial cell death. J Biol Chem. 2004;279:20221-20233.

20. Li H, Zhu H, Xu CJ, Yuan J. Cleavage of BID by caspase 8 mediates the mitochondrial damage in the Fas pathway of apoptosis. Cell. 1998;94:491-501.

21. Strassr A, O'Connor L, Dixit VM. Apoptosis signaling. Ann Rev Biochem. 2000;69:217-245.

22. Earnshaw WC, Martins LM, Kaufmann SH. Mammalian caspases: structure, activation, substrates and functions during apoptosis. Ann Rev Biochem. 1999;68:383-424.

23. Li P, Nijhawan D, Budihardjo I et al. Cytochrome $c$ and ATP-dependent formation of Apaf-1/caspase- 9 complex initiates an apoptotic protease cascade. Cell. 1997;91:479-489. 
24. Ysauda M, Umemura S, Osamura YR, Kenjo T, Tsutsumi Y. Apoptotic cells in the human endometrium and placental villi: pitfalls in applying the TUNEL method. Arch Histol Cytol. 1995;58:185-190.

25. Gavrieli Y, Sherman Y, Ben-Saaon SA. Identification of a programmed cell death in situ via specific labelling of nuclear DNA fragmentation. J Cell Biol. 1992;19:493-501.

26. Cohen GM, Sun XM, Snowden RT et al. Key morphological features of apoptosis may occur in the absence of internucleosomal DNA fragmentation. Biochem J. 1992;286:331-334.

27. Liu Y, Gao P, Xie Y. Role of placental apoptosis in fetal growth restriction. Zhonghua Fu Chan Ke Za Zhi. 2002; 37:721-722.

28. Levy R, Nelson DM. To be or not to be, that is the question: apoptosis in human trophoblast. Placenta. 2000;1:1-13.

29. Kar M, Ghosh D, Sengupta J. Histochemical and morphological examination of proliferation and apoptosis in human first trimester villous trophoblast. Hum Reprod. 2007;11:2814-2823.

30. Madazli R, Benian A, Ilvan S, Calay Z. Placental apoptosis and adhesion molecules expression in the placenta and the maternal placental bed of pregnancies complicated by fetal growth restriction with and without pre-eclampsia. $J$ Obset Gynaecol. 2006;26:5-10.

31. Enders AC, King BF. Early stages of trophoblastic invasion of the maternal vascular system during implantation in the macaque and baboon. Am J Anat. 1992;192:329-346.

32. Huppertz B, Hunt JS. Trophoblast apoptosis and placental development — a workshop report. Placenta. 2000;21:74-76.

33. Goldenberg RL, Hauth JC, Andrews WW. Intrauterine infection and preterm delivery. N Engl J Med. 2000;342:1500-1507.

34. Salafia CM, Weigl C, Silverman L. The prevalence and distribution of acute placental inflammation in uncomplicated term pregnancies. Obstet Gynecol. 1989;73:383-389.
35. Chellam VG, Rushton DI. Chorioamnionitis and funiculitis in the placentas of 200 births weighing less than $2.5 \mathrm{~kg} . \mathrm{Br}$ J Obstet Gynaecol. 1985;92:808-814.

36. Blanc WA. Pathology of the placenta, membranes and umbilical cord in bacterial, fungal and viral infections in man. Perinatal Diseases. Monogr Pathol. 1981;22:67-132.

37. Balkundi DR, Ziegler JA, Watchko JF, Craven C, Trucco M. Regulation of FasL/Fas in human trophoblasts: possible implications for chorioamnionitis. Biol Reprod. 2003;69:718-724.

38. Tanir HM, Sener T, Artan S, Kaytaz B, Sahin-Mutlu F, Ozen ME. Programmed cell death (apoptosis) in placentas from normal pregnancy and pregnancy complicated by term and preterm premature rupture of membranes. Arch Gynecol Obset. 2005;273:98-103.

39. Kataoka S, Furuta I, Yamada $\mathrm{H}$ et al. Increased apoptosis of human fetal membranes in rupture of the membranes and chorioamnionitis. Placenta. 2002;23:224-231.

40. Fortunato SJ, Menon R, Lombardi SJ. Amniochorion gelatinase-gelatinase inhibitor imbalance in vitro a possible infectious pathway to rupture. Obstet Gynecol. 2000;95:240-244.

41. George RB, Kalich J, Yonish B, Murtha AP. Apoptosis in the chorion of fetal membranes in preterm premature rupture of membranes. Am J Perinatol. 2008;25:29-32.

42. Hohlbaum AM, Gregory MS, Ju ST, Marshak-Rothstein A. Fas ligand engagement of resident peritoneal macrophages in vivo induces apoptosis and the production of neutrophil chemotactic factors. J Immunol. 2001;167:6217-6224 .

43. Yui J, Garcia-Lloret M, Wegmann TG, Guilbert LJ. Cytotoxicity of tumour necrosis factor-alpha and gamma-interferon against primary human placental trophoblasts. Placenta. 2000;15:819-835.

44. Zimmermann KC, Green DR. How cells die: apoptosis pathways. J Allergy Clin Immunol. 2001;108:99-103.

Submitted: 12 April, 2011 Accepted after reviews: 14 November, 2011 